\title{
Surgical Treatment of Idiopathic Multiple Pulmonary Arteriovenous Malformation Identified at the Onset of Cerebral Infarction: A Case Report
}

\author{
Masahiro Kitada*, Shunsuke Yasuda, Nana Takahashi, Satoshi Okazaki, Kei Ishibashi, \\ Satoshi Hayashi, Yoshinobu Ohsaki \\ Department of Respiratory Center, Asahikawa Medical University, Hokkaido, Japan \\ Email: *k1111@asahikawa-med.ac.jp, s-yasuda@asahikawa-med.ac.jp, kyokui080026@gmail.com, \\ syugoshin.19851221@gmail.com, kei_dod@hotmail.com, shayashi@asahikawa-med.ac.jp, yohsaki@asahikawa-med.ac.jp
}

How to cite this paper: Kitada, M., Yasuda, S., Takahashi, N., Okazaki, S., Ishibashi, K., Hayashi, S. and Ohsaki, Y. (2017) Surgical Treatment of Idiopathic Multiple Pulmonary Arteriovenous Malformation Identified at the Onset of Cerebral Infarction: A Case Report. Open Journal of Respiratory Diseases, 7, 62-67.

https://doi.org/10.4236/ojrd.2017.72007

Received: March 20, 2017

Accepted: May 12, 2017

Published: May 15, 2017

Copyright $\odot 2017$ by authors and Scientific Research Publishing Inc. This work is licensed under the Creative Commons Attribution International License (CC BY 4.0).

http://creativecommons.org/licenses/by/4.0/

\begin{abstract}
Pulmonary arteriovenous malformation (PAVM), which is asymptomatic in most cases, is often identified in patients with central nervous system disorders such as brain abscesses and/or cerebral infarctions. We have reported a patient with idiopathic multiple PAVM identified at the onset of cerebral infarction. A 69-year-old woman visited the Department of Neuropathic Internal Medicine at our hospital with chief complaints of numbness in her left hand and a feeling of weakness. The patient was given a diagnosis of subacute cerebral infarction. Multiple old lacunar infarctions were also observed in the deep white matter of the left frontal lobe. Chest computed tomography showed multiple nodular structures, mainly in the right lower lung field (S8), as well as continuous arteries and veins at the site; thus, the patient was finally diagnosed with multiple PAVM. Right lower thoracoscopic lobectomy was performed, as is typical surgical practice in such cases. The patient had a favorable postoperative course, and had no recurrence of cerebral infarction. Although the patient's lesions were mainly restricted to $\mathrm{S} 8$, the fact that there were multiple lesions deemed a lobectomy as the appropriate course of treatment. This case emphasizes that attention should be paid to cases of multiple PAVM since cerebral infarction may arise from the disease.
\end{abstract}

\section{Keywords}

Pulmonary Arteriovenous Malformation (PAVM), Brain Abscesses, Cerebral Infarctions 


\section{Introduction}

Pulmonary arteriovenous malformation (PAVM), which is asymptomatic in most cases, is often identified in patients with central nervous system disorders such as brain abscesses and/or cerebral infarctions, in addition to patients with blood-stained sputum and hypoxemia-induced dyspnea or polycythemia. In Europe and the United States, hereditary hemorrhagic telangiectasia (HHT) is concurrently found in $60 \%-80 \%$ of patients [1] [2]. The mortality rate of this disease is high, at around 10\%, and aggressive treatment such as interventional radiology (IVR) and surgery is recommended immediately after diagnosis [3]. We describe our experience with a surgical case of idiopathic multiple PAVM which was identified at the onset of cerebral infarction.

\section{Case}

A 69-year-old woman visited the Department of Neuropathic Internal Medicine at our hospital with chief complaints of numbness in her left hand and a feeling of weakness. Although the patient had previously experienced a few atonic seizures, she had recovered in 1 to 2 hours and did not visit the hospital. The patient had no history of recurrent epistaxis, and was $153 \mathrm{~cm}$ in height and $46 \mathrm{~kg}$ in weight. There was no heart murmur, and respiratory sound was clear. There were no abnormal findings in her chest and abdomen and no capillary dilatation in her skin or mucosa. The patient did not exhibit quadriplegia. Magnetic resonance imaging taken at the first visit showed high signal intensities in the right centrum semiovale and the precentral gyrus on the diffusion-weighted images, and high signal intensities were also seen on fluid attenuated inversion recovery images. The patient was given a diagnosis of subacute cerebral infarction. Multiple old lacunar infarctions were also observed in the deep white matter of the left frontal lobe (Figure 1). Chest computed tomography showed multiple nodular structures, mainly in the right lower lung field (S8), as well as continuous arteries and veins at the site; thus, the patient was finally diagnosed with multiple PAVM (Figure 2 and Figure 3). Although IVR was first considered, multiple, relatively widespread lesions were observed in the peripheral lung field; therefore, right lower thoracoscopic lobectomy was performed, as is typical surgical practice in such cases. The patient had a favorable postoperative course, and had no recurrence of cerebral infarction. Pathological examination revealed no neoplastic change, and the diagnosis of multiple PAVM was confirmed (Figure 4). There were small and large arteriovenous lesions along the bronchus leading to the lower lobe, primarily in S8. Three years after surgery, no signs of recurrence have been observed.

\section{Discussion}

PAVM is a congenital or acquired abnormal intrapulmonary arteriovenous shunting. In Europe and the United States, $80 \%$ of patients with PAVM are reportedly congenital in nature, and $47 \%-80 \%$ have HHT, which is an autosomal dominant inheritance [1] [4]. Although some cases of PAVM are caused by 


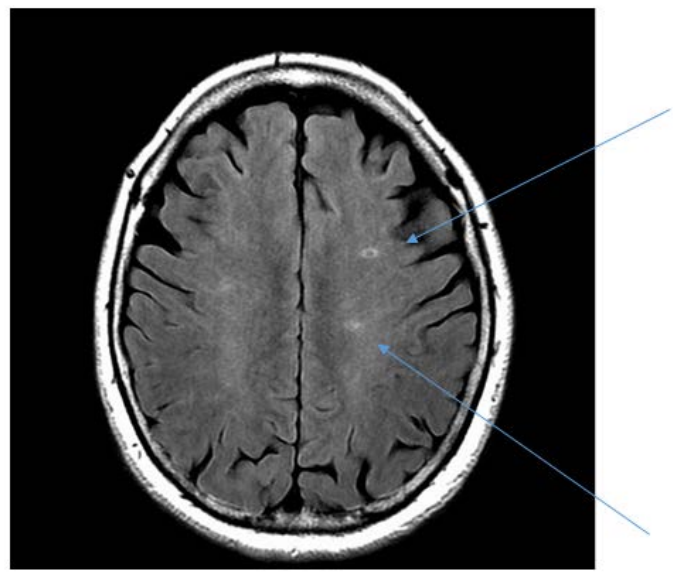

Figure 1. Magnetic resonance imaging (DW2 FLAIR). Multiple old lacunar infarctions were also observed in the deep white matter of the left frontal lobe. Arrows are acute infarct lesions.

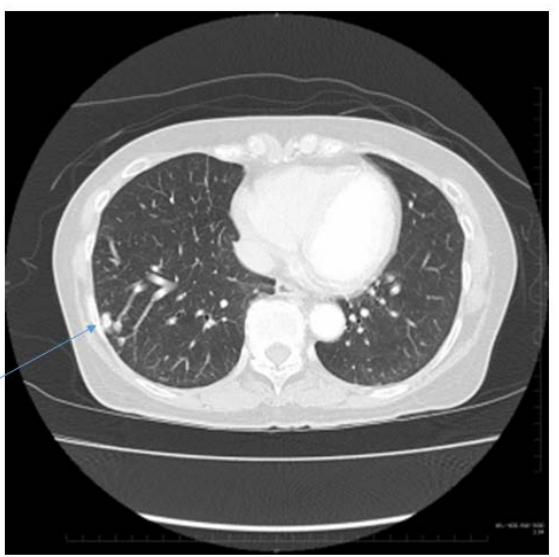

Figure 2. Chest computed tomography. Chest computed tomography showed multiple nodular structures, mainly in the right lower lung field (S8), as well as continuous arteries and veins at the site; thus, the patient was finally diagnosed with multiple PAVM.

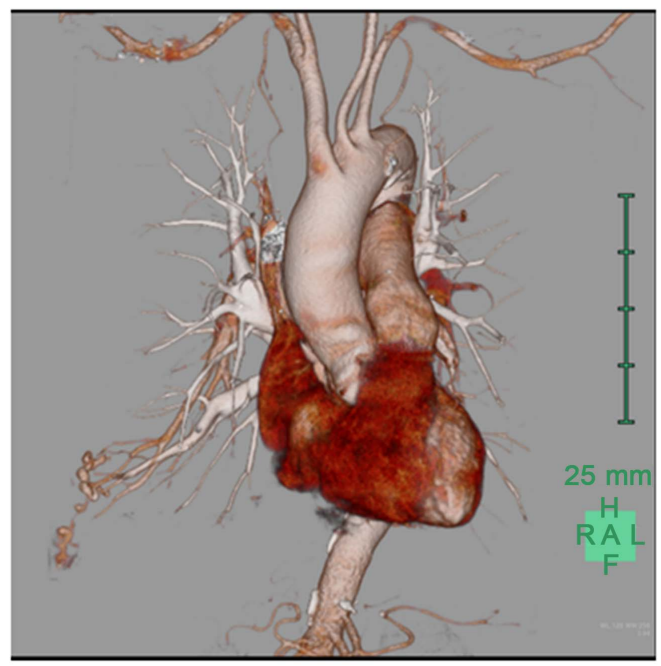

Figure 3. CT angiography. Nodule-like structures occur frequently in the vicinity of the bronchial bifurcation and continue with the peripheral pulmonary artery and vein. 


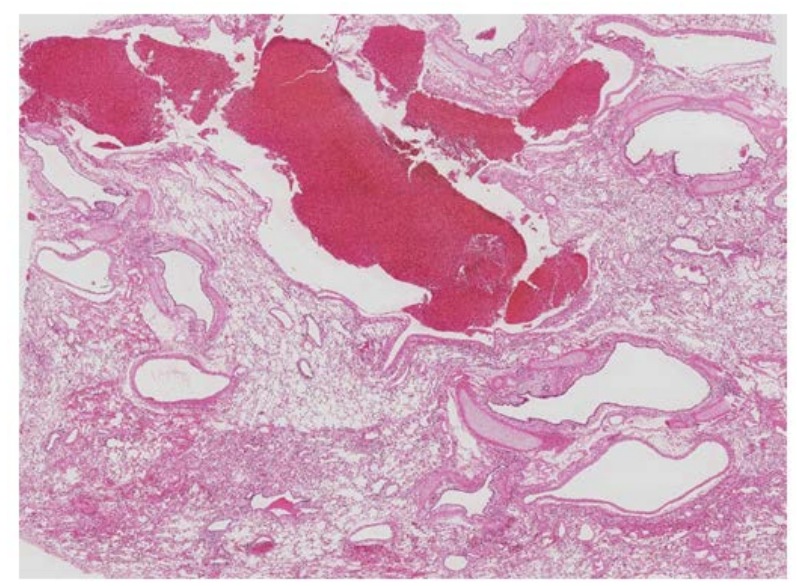

Figure 4. Pathological findings. Pathological examination revealed no neoplastic change, and the diagnosis of multiple PAVM was confirmed. Abnormal vessels spreading to the vicinity of the bifurcation of the lower bronchial lobe are recognized.

trauma, liver cirrhosis, paragonimiasis, and malignant tumors [5], the case presented here was considered idiopathic because the patient presented with no symptoms suggestive of HHT or other causes such as recurrent epistaxis, capillary dilatation in the skin and mucosa, or arteriovenous malformations of the lung, liver, brain, gastrointestinal tract, or spinal cord.

The symptoms of PAVM are often nonspecific and respiratory in nature. Such symptoms include respiratory discomfort, cough, chest pain, malaise, and blood-stained sputum. In addition, the central nervous system is affected in approximately $30 \%$ of patients in the form of stroke, transient ischemic attacks, and brain abscesses [1] [2]. The mechanisms underlying brain abscesses and cerebral infarctions include: 1) decreased resistance to infection in brain tissues due to hypoxemia; 2) development of ischemia or infarction in the brain due to polycythemia-induced embolizationa; and 3) septic emboli, often reaching the brain through the fistula [6]. The incidence of cerebral infarction is reportedly $32 \%$ in single PAVM and 60\% in multiple PAVM [7]. This case was also found in the symptoms of repeated cerebral infarction.

Treatment of PAVM is indicated for a size cut-off of $\geq 3 \mathrm{~mm}$ for the feeding artery when the risk of cerebral infarction is high [8]. Although IVR is commonly the first-line therapy [9], and about $16 \%$ of patients experience recurrence [10]. Moreover, the following complications have been reported: thrombosis, cerebral infarction by coil migration, brain abscesses (the left cardiac system to the brain), coil protrusion into the aorta, rupture of a fragile venous sac, outflow of arteriovenous thrombi, and pulmonary infarction caused by obstruction of the pulmonary artery bifurcating to the normal lung. Therefore, surgical resection is recommended for patients with multiple pulmonary arteriovenous malformations, such as our patient presented here. Thoracoscopic surgery has been performed in many institutions over recent years [11]. However, in order to recommend such surgery, the lesion needs to be benign and the extent of resection should be as small as possible; therefore, partial resection is commonly per- 
formed. In the present case, since lesions were spread around the bronchus in S8 to the lower lobe bronchus, a lobectomy was considered appropriate.

\section{Conclusion}

We have reported a patient with idiopathic multiple PAVM identified at the onset of cerebral infarction. Although the patient's lesions were mainly restricted to S8, the fact that there were multiple lesions deemed a lobectomy as the appropriate course of treatment. This case emphasizes that attention should be paid to cases of multiple PAVM since cerebral infarction may arise from the disease.

\section{Consent}

Written informed consent was obtained from the patients for publication of this case report and any accompanying images. A copy of the written consent is available for review by the Editor-in Chief of this journal

\section{Authors Contribution}

MK have operated this case and analyzed all data. SY, NT, KI, SH and YO did the assistant of the operation. All authors read and approved the final manuscript.

\section{Competing Interests}

The authors declare that they have no competing interests.

\section{References}

[1] Faughnan, M.E., Granton, J.T. and Young, L.H. (2009) The Pulmonary Vascular Complications of Hereditary Haemorrhagic Telangiectasia. European Respiratory Journal, 33, 1186-1194. https://doi.org/10.1183/09031936.00061308

[2] Moussoutas, M., Fayad, P., Rosenblatt, M., Hashimoto, M., Pollak, J., Henderson, K., et al. (2000) Pulmonary Arteriovenous Malformations. Cerebral Ischemia and Neurologic Manifestations. Neurology, 55, 959-964. https://doi.org/10.1212/WNL.55.7.959

[3] Lacombe, P., Lacout, A., Marcy, P.Y., Binsse, S., Sellier, J., Bensalah, M., et al. (2013) Diagnosis and Treatment of Pulmonary Arteriovenous Malformations in Hereditary Hemorrhagic Telangiectasia: An Overview. Diagnostic and Interventional Imaging, 94, 835-848. https://doi.org/10.1016/j.diii.2013.03.014

[4] Gossage, J.R. and Kanj, G. (1998) Pulmonary Arteriovenous Malformations. American Journal of Respiratory and Critical Care Medicine, 158, 643-661. https://doi.org/10.1164/ajrccm.158.2.9711041

[5] Wong, H.H., Chan, R.P., Klatt, R. and Faughnan, M.E. (2011) Idiopathic Pulmonary Arteriovenous Malformations: Clinical and Imaging Characteristics. European Respiratory Journal, 38, 368-375. https://doi.org/10.1183/09031936.00075110

[6] Meacham, W.F. and Scott, H.W.Jr. (1958) Congenital Pulmonary Arteriovenous Aneurysm Complicated by Bacteroides Abscess of Brain: Successful Surgical Management. Annals of Surgery, 147, 404-408. https://doi.org/10.1097/00000658-195803000-00017

[7] Moussouttas, M., Fayad, P., Rosenblatt, M., Hashimoto, M., Pollak, J., Henderson, 
K., Ma, T.Y. and White, R.I. (2000) Pulmonary Arteriovenous Malformations: Cerebral Ischemia and Neurologic Manifestations. Neurology, 55, 959-964.

https://doi.org/10.1212/WNL.55.7.959

[8] Kimura, K., Minematsu, K. and Nakajima, M. (2004) Isolated Pulmonary Arteriovenous Fistula without Rendu-Osler-Weber Disease as a Cause of Cryptogenic Stroke. Journal of Neurology Neurosurgery and Psychiatry, 75, 311-313.

[9] Cottin, V., Chinet, T., Lavolé, A., Corre, R., Marchand, E., Reynaud-Gaubert, M., Plauchu, H. and Cordier, J.F. (2007) Groupe d'Etudes et de Recherche sur les Maladies "Orphelines" Pulmonaires (GERM"O"P). Pulmonary Arteriovenous Malformations in Hereditary Hemorrhagic Telangiectasia: A Series of 126 Patients. Medicine (Baltimore), 86, 1-17. https://doi.org/10.1097/MD.0b013e31802f8da1

[10] Lee, D.W., White, R.I.Jr, Egglin, T.K., Pollak, J.S., Fayad, P.B., Wirth, J.A., Rosenblatt, M.M. and Dickey, K.W. (1997) Embolotherapy of Large Pulmonary Arteriovenous Malformations: Long-Term Results. Annals of Thoracic Surgery, 64, 930-940. https://doi.org/10.1016/S0003-4975(97)00815-1

[11] Minami, M, Fujii, Y., Mizuta, T., Kishima, H. and Matsuda, H. (1996) Video-Assisted Thoracoscopic Local Excision of Pulmonary Arteriovenous Fistula. The Journal of Thoracic and Cardiovascular Surgery, 112, 1395-1397. https://doi.org/10.1016/S0022-5223(96)70161-7

\section{Scientific Research Publishing}

Submit or recommend next manuscript to SCIRP and we will provide best service for you:

Accepting pre-submission inquiries through Email, Facebook, LinkedIn, Twitter, etc. A wide selection of journals (inclusive of 9 subjects, more than 200 journals) Providing 24-hour high-quality service User-friendly online submission system Fair and swift peer-review system Efficient typesetting and proofreading procedure Display of the result of downloads and visits, as well as the number of cited articles Maximum dissemination of your research work

Submit your manuscript at: http://papersubmission.scirp.org/ Or contact ojrd@scirp.org 